\title{
IMPACT FROM ROAD TRANSPORT OF "HIGH LEVEL" RADIOACTIVE WASTES IN SPAIN
}

\author{
J.A. CALLEJA ${ }^{1, *}$ \\ F. GUTIÉRREZ ${ }^{2}$ \\ C. COLÓN ${ }^{3}$
}

\author{
${ }^{1}$ Prevention Service, Tecnatom, Avda Montes de Oca 1 \\ 28703 San Sebastián de los Reyes, Madrid, Spain \\ Dept. Ingeniería Eléctrica, UPM, Rda Valencia 3, 28012 Madrid, Spain \\ ${ }^{2}$ Dept. Química Industrial y Polímeros, UPM, Rda Valencia 3 \\ 28012 Madrid, Spain \\ ${ }^{3}$ Dept. Física Aplicada, UPM, Rda Valencia 3 \\ 28012 Madrid, Spain
}

Received: $16 / 11 / 11$

Accepted: 09/03/12 *to whom all correspondence should be addressed:

e-mail: jacalleja@tecnatom.es

\begin{abstract}
This work focuses in transport of high level radioactive wastes, mainly consisting of spent fuels from nuclear power utilities in Spain. To date, these wastes are being stored in the own generating facilities, or they are sent to France; but these options are not any more technically or economically sustainable, thus a central repository has been planned in the country -its final location just decided in November 2011- so that we have chosen this site to advance in the studies.

The objectives are to describe the logistics of these transports and estimate their associated radiological impacts: eight routes are considered, corresponding to the nuclear power installations in Spain, plus the return of spent fuels which are also temporary stored in France; calculation of impacts is based in the radiation index of transport, speed and distances, populations exposed, the corresponding doses and average values of risk.

We have developed a computer application, which needs only to enter the radiation level at $1 \mathrm{~m}$ from the transport and select the route; thus the radiological impacts are automatically obtained, concluding that they are irrelevant in normal conditions of transports, while the program (web available) can be useful for further analysis of such operations.
\end{abstract}

KEYWORDS: high-level nuclear transports, central storage facility, radioactive impacts, radiological protection, health detriment, environmental management.

\section{INTRODUCTION}

Transports of radioactive wastes in Spain are becoming issues of renewed interest, due to the increased mobility of these materials which can be expected after the building and operation of the planned central repository for this country in a near future. Such types of residues will be mainly of the medium and high activity classes and have raised concerns on the safety of operations, the radiological protection of individuals, the compliance with legal regulations and their environmental consequences of all kind (Law 31/95, 1995).

These issues are of special relevance in transport of high level radioactive wastes (HLW), mainly coming from the spent fuels of nuclear power stations. Typical composition of this waste is: $94.7 \%$ uranium (0.7\% U-235), $4.1 \%$ fission products, $1.1 \%$ plutonium and $0.1 \%$ minor actinides; it is a solid product which decays its activity with time and which is generated in relatively small quantities (about $5 \mathrm{~g}$ per person-year in the European Union). 
But a long 'radioactive route' of more than $2000 \mathrm{~km}$ for transporting spent nuclear fuels can be expected in Spain, presumably by road, from current and decommissioned power facilities to the planned central repository (ATC) to be located in Villar de Cañas (Cuenca).

In this study, relevant information for the assessment of radiological risk of road transport were taken into account, as the sources and destination of the radioactive transports, the amount of traveling to be done, the preferred routes and populations affected, the characterization of residues and containers, their corresponding testing, etc. These data were supplied by different organizations fully related with these activities, like the nuclear power stations, the companies in charge of radioactive transports, the enterprises for inspection and control of these activities, etc., as well as the government institutions which are responsible for the selection and location of the storage facility and other decisions on the nuclear policies of the country.

Thus, we have developed a program for computing data in such a form that by entering the radiation level at 1 meter of the transport load and by choosing a particular displacement, the computer application is capable to calculate the corresponding radiological effects, like the global estimated impact, its relevance to population in general or on people living and driving near the main roads, the doses received by the most exposed individuals (e.g. workers or drivers), or the probability of detrimental on human health.

The results could be useful for better understanding and management of these activities and their related impacts; at the same time that the generated reports are considered of particular interest as innovative and complementary information to the current legal documentation, which is basically required for transporting radioactive wastes in the country, according with the international safety rules (like IAEA and ADR).

Though main studies are in progress, as the definite location for the Spanish storage facility has just been decided, preliminary results with the existing transports of residues of medium activity indicate that the radiological impact is very low in conventional operations (Calleja and Gutiérrez, 2010). Nevertheless, the management of these transports is complex and laborious, making it convenient to progress further in the analysis and quantification of this kind of events, which constitutes the main objective of the present study for HLW radioactive road mobility in Spain.

\section{TRANSPORT REGULATIONS FOR HLWS}

Transports of HLWs are regulated by a series of internationally accepted documents based on the IAEA safety standard ("Regulations for the Safe Transport of Radioactive Materials" TS-R-1) and the European agreement for carriage of dangerous goods by road (ADR, 2007). Safety regulations for transport in these documents lie above all on containers (shielding for gamma and neutron radiation, maintenance of subcritical conditions and cooling the heat emitted by fuels' decay), stipulating the types $B(U)$ and $B(M)$, and establishing design criteria approved by the regulatory body in accordance with the activity and physical form of the radioactive materials.

During the construction of containers, it is necessary to check the behaviour of materials exposed to extreme conditions of neutron irradiation, which usually experience a loss of ductility due to alterations of microstructure. Weakening and embrittlement are phenomena governed by the interaction of multiple variables, like the material type, its composition, initial structure, irradiation temperatures, flow and neutronic spectrum (Prosanz, 2005).

Another fundamental requirement is the training of drivers for vehicle transports, as well as monitoring and control by safety counsellors (RD 1566, 1999).

\section{EVALUATION METHODOLOGY}

The methodology used in this study is based on 'descriptive-explanatory methods', which allow the observation and collection of data by means of 'case study' approaches (Chetty, 1996; Yin, 1994). The aim is to describe systematically the logistics for HLW transports and their associated radiological impacts. We have chosen the transport of spent nuclear fuels in this case due to its complexity in the sphere of radioactive transports, as well as for the controls imposed by the regulatory body, the relevant framework that regulates it and for its importance within the current national energy scenario.

There are six nuclear power plants in operation in Spain: Cofrentes, Garoña, Vandellos II, Trillo, Almaraz and Ascó (Spanish NPPs, 1995), with a total of 8 reactors, and one plant that has been declared definitively shut down (Jose Cabrera); according with the government commitment and 
action plan, wastes from all these facilities will be shipped to a central temporary repository to be located and built before long.

We began by establishing the number of transports that are to be performed annually: in total "8 routes" for transporting high level wastes are considered, along which "48 movements" that should be made during the annual period under review (ATC, 2006); we identified the provinces affected by the transport routes, the distances travelled and time taken, along with the population in each route and national (with regard to the last point, only the exposed population of all routes were taken into account, leaving aside Galicia, Cantabria, the Basque Country, Navarra, Murcia and Andalucía).

Although the main objective of this study is to evaluate the radiological exposure of population from the emission of ionizing radiations associated with HLW transport, it also aims to determine the probability of health risks. The radiations produce ionization upon passing through the tissues of living organisms and this disturbs the chemical behaviour of the constituents of affected cells, some of which can regenerate while others may be damaged; although the exposed individuals are not bound to suffer cancer or genetic injuries, they run a higher risk than non-irradiated persons and this risk increases with the doses (Ortega and Jorba, 1988).

To make widely applicable estimates, the International Commission on Radiological Protection recommends a series of values of risk, obtained from populations of different continents and countries (Recommendations ICRP, 1999); the average of these values, regarding the probability of death by cancer, is " $5 \%$ per Sievert in a population of all ages, as long as the doses and dose rates in question are low".

In order to assess quantitatively the biological damage, an equivalent dose scale is used which measures the biological effects produced by the ionizing radiations in living organisms (Tanarro, 1986). In the case of this study, these are gamma and neutron emissions.

\section{CALCULATION PROGRAM FOR RADIOLOGICAL IMPACTS}

As a novel contribution, we present a computer application for treatment of data studied, along with a summary sheet: "Radiological impacts associated with the transport of high level radioactive wastes in Spain", where the main calculations are based in the transport index (radiation level at $1 \mathrm{~m}$ of transport), the exposure times and the populations affected (see figures and table).

This is perhaps the most interesting part of this work and constitutes a step forward in the study of impacts, serving also to complement the required documentation for this kind of operations. The application is based in an interactive "web map", which includes all the necessary geographical and demographical information to configure the different routes and input materials; it can be easily accessed in the web (http://impactoradiologico.com/) in order to facilitate the simulation of any proposed transport scenarios.

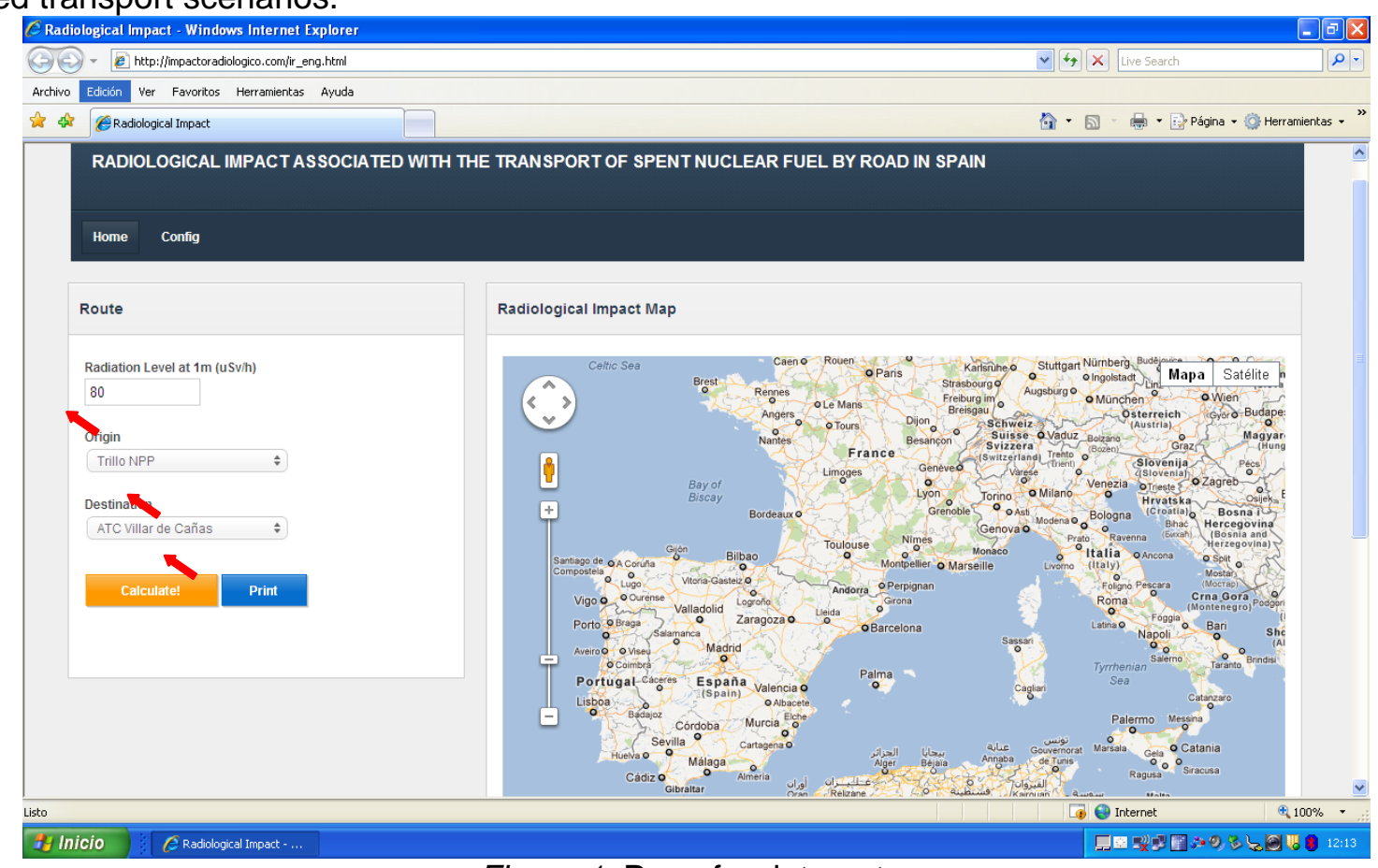

Figure 1. Page for data entry 


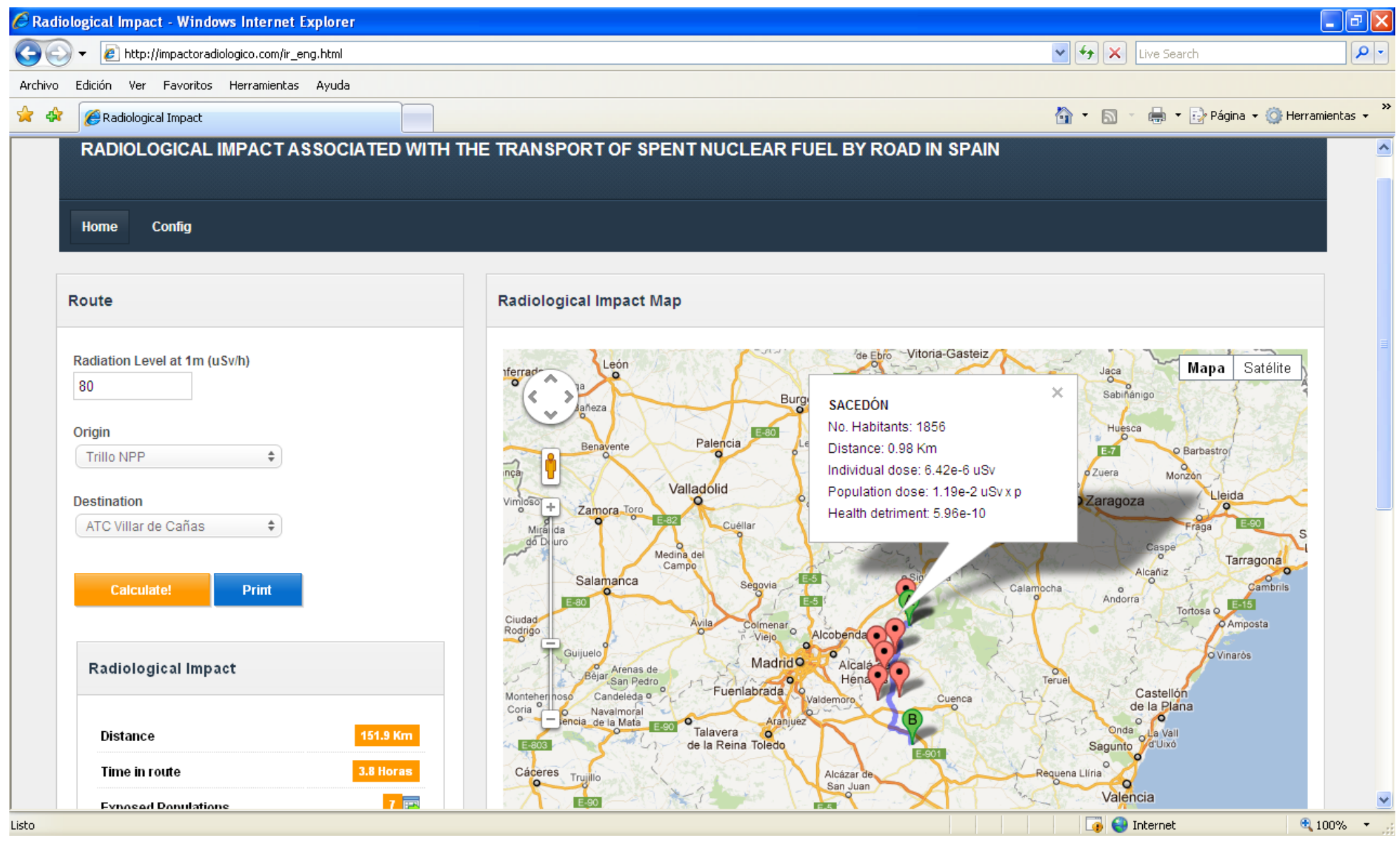

Figure 2. Page of results 
With the programme, one has only to enter the radiation levels measured at $1 \mathrm{~m}$ from the cargo vehicles and choose the routes (Figure 1), data which are all supplied by the shippers. Thus, the associated radiological impacts are automatically obtained (Figure 2). In the table we have just aggregated the impacts for all the movements which are expected in a reference year, as estimated by the programme (Table 1).

As the final location of the ATC in Spain has finally been determined, we use this destination to define the routes (i.e. the municipality of Villar de Cañas in Cuenca).

\section{IMPACT OF HLWS ROAD TRANSPORTS IN SPAIN}

Negative impacts associated with this kind of transports affect the environment, especially the living organisms exposed to radiations and in particular human health. The estimated total impact caused by the ionizing radiations, as sum of the number of transports per hours travelled and per the radiation levels at a distance of $1 \mathrm{~m}$ away from the vehicle, is $34.48 \mathrm{mSv} \cdot \mathrm{a}^{-1}$ (Table 1); which is within the permitted annual legal limit for professional exposures to ionizing radiations in Spain $\left(50.00 \mathrm{mSv} \cdot \mathrm{a}^{-1}\right)$, and it is also of the same order as for transports of radioactive materials not associated with spent fuels (46.64 $\left.\mathrm{mSv} \cdot \mathrm{a}^{-1}\right)$ (Calleja and Gutierrez, 2011).

The dose which an individual can receive (e.g. the drivers or passengers of other vehicles that coincides with the transport of radioactive materials) is $4.12 \mu \mathrm{Sv} \cdot \mathrm{a}^{-1}$. This is comparable to the estimations of other studies (Tanaboylu et al., 2001), indicating that the radiation doses for persons located $10 \mathrm{~m}$ away from the circulation route of spent nuclear fuels travelling at $20 \mathrm{~km} \mathrm{~h}^{-1}$ would be only $0.025 \mu \mathrm{Sv}$.

The impact on the "exposed group" (INE, 2008), located in regions through which the transport passes (national impact), applied to all residents of the different provinces is $1.92 \cdot 10^{-3} \mu \mathrm{Sv} \cdot \mathrm{a}^{-1}$. This is also comparable to the studies of environmental impact statement for transport of spent nuclear fuels to the deep geological repository in Yucca Mountain (U.S. DOE, 2002), which considers that the average dose to members of the public would be $0.005 \mu \mathrm{Sv} \cdot \mathrm{a}^{-1}$.

Probability for the most exposed individuals developing a severe illness (cancer), resulting from exposure to radiations, is $2.06 \cdot 10^{-7}$, and $9.69 \cdot 10^{-11}$ if considered at national level. This figure is obtained as the product of the dose received by the general public and the probability of death from cancer of $5 \%$ per Sv in a population of all ages, provided that the dose and dose rates are low.

In a recent epidemiological study of the possible health effects of ionizing radiations arising from the operation of the Spanish nuclear fuel cycle and radioactive facilities, on population living in the areas surrounding such installations (NSC, 2010) the "effective dose", was proposed as an indicator of exposure, since several external exposure paths for the radiations were identified along with others such as liquid and gaseous effluents that can be incorporated into the human body.

Although units for description of overall impact are proposed in equivalent doses $(\mu \mathrm{Sv})$, it would be better to express them in units of exposure or absorbed dose ( $\mu \mathrm{Gy})$, since doses may or may not be acquired by human beings (depending on whether they are or not in areas of exposure). Anyway, in the case of gamma emission the exposure is similar to the absorbed dose and the same as the equivalent dose. Consequently, as values for the radiation level one metre away from the transport vehicle are measured in units of equivalent dose, the impacts obtained in this study are expressed in such units in all cases.

As vehicles are usually in motion, the doses $(D)$ at a point $P$ produced by the moving source can be obtained in function of the transport index (IT) and distance from the radioactive material to P (Fig. 3).

$$
\begin{aligned}
& \mathrm{D}(\mathrm{P})=\mathrm{k} \frac{\mathrm{A}}{\mathrm{d}_{1}^{2}} \\
& D(P)=D(B) \frac{d_{2}^{2}}{d_{1}^{2}} \quad D(P)=\frac{I T}{d_{1}^{2}} \quad d_{1}^{2}=v^{2} \times t^{2}+b^{2} \\
& \mathrm{IT}=\text { transport index, the radiation level at } d_{2}=1 \mathrm{~m} \text { from the source }\left(\mu \mathrm{Sv} \mathrm{h} \mathrm{h}^{-1}\right) \\
& \mathrm{b}=\text { distance to the vehicle }(\mathrm{m}) \\
& v=\text { speed of the vehicle }\left(\mathrm{m} \mathrm{h}^{-1}\right)
\end{aligned}
$$

In order to maintain dimensional consistency, we introduce a constant $\left(K_{d}\right)$ whose value is $1 \mathrm{~m}^{2}$; thus, the dose produced by the moving source along the entire trajectory is obtained by integrating the expression: 


$$
\begin{aligned}
& \int d D(P)=\int_{0}^{\infty} K_{d} \times I T /\left(v^{2} \times t^{2}+b^{2}\right) d t=K_{u} \times I T / b \times v(\operatorname{arctg} v \times t / b) \\
& D(P)=\pi \times I T \times K_{d} / b \times v
\end{aligned}
$$

The last expression is used to calculate the exact radiation doses that a group of people would receive when they are located at a given distance from the transport vehicle moving at speed $v$.

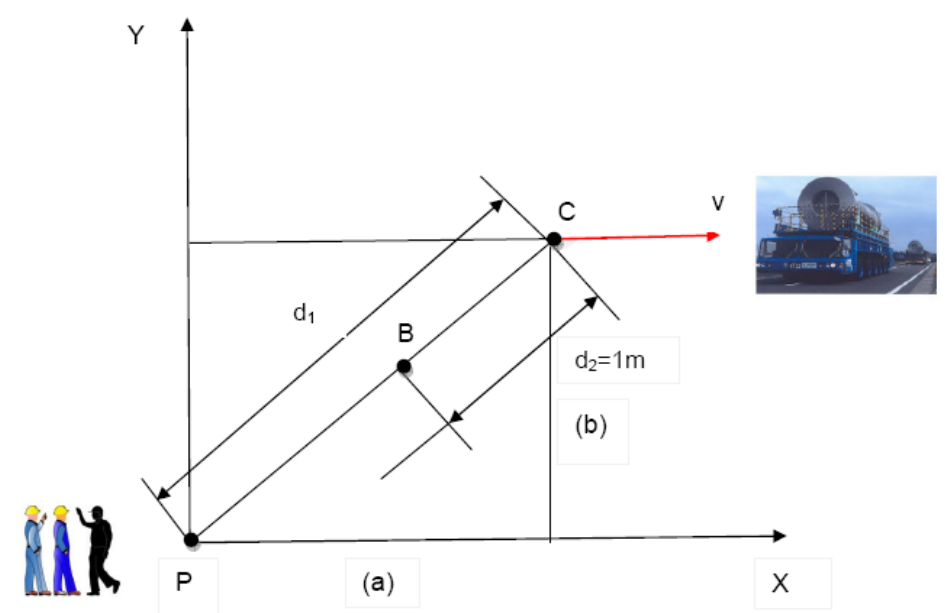

Figure 3. Dose produced at one point by a moving vehicle carrying radioactive materials

If we focus on the impact generated upon national population, taking into consideration:

- the overall dose of $34.48 \mu \mathrm{Sv} \cdot \mathrm{a}^{-1}$, calculated according to the radiation level at $1 \mathrm{~m}$, for a speed of $40 \mathrm{~km} \mathrm{~h}^{-1}$ (in accordance with the road safety guidelines for this type of transport),

- and impact distance of approximately $1 \mathrm{~km}$ (radius within the bulk of population of big cities like Madrid or Barcelona may be found, i.e. the most significant groups),

we can obtain:

$D(P)=\pi \times 34.48 / 40000=2.70 \cdot 10^{-3} \mu \mathrm{Sv} \cdot \mathrm{a}^{-1}$

which is similar to the dose that we had already obtained of $1.92 \cdot 10^{-3} \mu \mathrm{Sv} \cdot \mathrm{a}^{-1}$ (Table 1).

These calculations are just general estimates in terms of distances, vehicle speed, location of the population, etc. Nevertheless, the objective is to compare the differences between the initial treatment of data and its calculation using more elaborated processes; though, as it was observed, the two sets of data are similar.

Finally, with ionizing emissions there are processes of mitigation according to distances, i.e., as we move away from the emitting source, the radiation level decreases.

As assumed, the dose rates decrease with the inverse squares of the distances from the packages. However, this is not entirely valid, as the containers for spent fuels are typically about $5 \mathrm{~m}$ long and 2 $\mathrm{m}$ in diameter; thus, they do not represent point sources at $1 \mathrm{~m}$, and dose rates will initially decrease more slowly with the distances. Only at a distance of several metres, the 'inverse square law' becomes a suitable approximation; however, when the distances are greater than a few tens of metres, photon scattering and absorption phenomena in air will become appreciable and the dose rates will fall off more rapidly than the square law.

In this paper, "distance" is proposed as main indicator, on the basis of the attenuation achieved in the process of emission, being in opinion of the authors the most appropriate approach in this case, since we dealt only with external exposures to the ionizing radiations. 
Table 1. Expected annual radiological impacts from road transport of high level radioactive wastes in Spain

RADIOLOGICAL IMPACTS ASSOCIATED WITH THE TRANSPORT OF HLWS IN SPAIN

\begin{tabular}{|c|c|c|c|c|c|c|c|}
\hline ROUTES & $\begin{array}{l}\text { Total dose } \\
\text { impact } \\
\left(\mu \mathrm{Sv} \cdot \mathrm{a}^{-1}\right)\end{array}$ & $\begin{array}{l}\text { Dose to most } \\
\text { exposed } \\
\text { individual } \\
\left(\mu \mathrm{Sv} \cdot \mathrm{a}^{-1}\right)\end{array}$ & $\begin{array}{l}\text { Dose to public } \\
\text { (impact on } \\
\text { route) } \\
\left(\mu \mathrm{Sv} \cdot \mathrm{a}^{-1}\right)\end{array}$ & $\begin{array}{l}\text { Dose to public } \\
\text { (national } \\
\text { impact) } \\
\left(\mu \mathrm{Sv} \cdot \mathrm{a}^{-1}\right)\end{array}$ & $\begin{array}{l}\text { Detriment to } \\
\text { health } \\
\text { (most exposed } \\
\text { individual) }\end{array}$ & $\begin{array}{l}\text { Detriment to } \\
\text { health } \\
\text { (public on } \\
\text { route) }\end{array}$ & $\begin{array}{l}\text { Detriment to } \\
\text { health } \\
\text { (national } \\
\text { impact) }\end{array}$ \\
\hline $\begin{array}{c}\text { FROM NUCLEAR } \\
\text { POWER PLANTS } \\
\text { TO CENTRALISED } \\
\text { REPOSITORY }\end{array}$ & 27101 & 4.64 & 7.,20 E-03 & 1.59 E-03 & $2.32 \mathrm{E}-07$ & $3,65 \mathrm{E}-10$ & $7.95 \mathrm{E}-11$ \\
\hline \multicolumn{8}{|l|}{ ATC Villar de Cañas } \\
\hline $\begin{array}{c}\text { FROM FRANCE } \\
\text { THROUGH LA } \\
\text { JUNQUERA } \\
\text { (VITRIFIED FUEL) } \\
\text { TO CENTRALISED } \\
\text { REPOSITORY }\end{array}$ & 7380 & 3.60 & $9.30 \mathrm{E}-04$ & 3.33 E-04 & $1.80 \mathrm{E}-07$ & $4.65 \mathrm{E}-11$ & $1.67 \mathrm{E}-11$ \\
\hline \multicolumn{8}{|l|}{ ATC Villar de Cañas } \\
\hline OVERALL & 34481 & 4.12 & N/A & 1.92 E-03 & 2.06 E-07 & N/A & $9.69 \mathrm{E}-11$ \\
\hline
\end{tabular}

Overall dose impact: =Value obtained from the 'contribution of all shipments performed on all the routes'. Impacts $(\mu \mathrm{Sv})$ : index of transport $\left(\mu \mathrm{Sv} \mathrm{h}^{-1}, 1 \mathrm{~m}\right) \times$ time in route [= prescribed speed $\left(40 \mathrm{~km} \mathrm{~h}^{-1}\right) \times$ course $(\mathrm{km})]$.

Dose of most exposed individual: $=\mathrm{IT}\left(\mu \mathrm{Sv} \mathrm{h}^{-1}\right) \times$ driving manoeuvres $(5$ seconds $\times 7$ overtaking on route). Transport travels at $40 \mathrm{~km} \mathrm{~h}^{-1}$ and private vehicles, truck or car, at $90 \mathrm{~km} \mathrm{~h}^{-1}$ on the longest route; we assume that drivers of private vehicles travel on the route at the same time as radioactive material is transported.

Dose to public: Consideration is given to the population of all ages living in the provinces through which the shipment passes. Dose to public on route $\left(\mu \mathrm{Sv} \mathrm{p}^{-1}\right)$ : total impact $(\mu \mathrm{Sv}) /$ population weight $(p)$.

Dose to public, national impact: Population of all ages in the national environment, subjected to impact. Dose to public national $\left(\mu \mathrm{Sv} \mathrm{p}^{-1}\right)$ : total impact $(\mu \mathrm{Sv}) /$ all population risk (p).

Health detriment (death by cancer): the average value as regards probability of death by cancer is $5 \%$ per Sv in a population of all ages. Detriment to health: doses $\left(\mu \mathrm{Sv} \mathrm{p}^{-1}\right) \times$ probability of cancer $\left(5 \cdot 10^{-8} / \mu \mathrm{Sv}^{-1}\right)$.

\section{CONCLUSIONS}

As a first conclusion of this work, it has been demonstrated that ionizing radiations generated by transports of high level radioactive wastes in Spain are not significant in terms of producing adverse effects for human health. Furthermore, in normal conditions of the transports, the annual overall radiological impact is very low and has a negligible effect.

Secondly, the radiological impacts associated with transportation of HLWs can be calculated by a new software application for processing the data on selected input materials and routes. This application is now free available in the web and it has been conceived as a useful tool to advance in the analysis of impacts from such operations and to supplement the legal documentation required for this type of transports, if deemed necessary

\section{ACKNOWLEDGEMENTS}

Authors are gratefully acknowledged to the radiological protection personnel of the Spanish nuclear plants. 


\section{REFERENCES}

ADR (2007), European Agreement on the International Road Transport of Hazardous Goods, BOE, supplement of January $21^{\text {st }} 2007$.

Calleja J.A. and Gutiérrez F., (2010), Impacto radiológico asociado al transporte de materiales radiactivos por carretera en España, Radioprotección, 17, 46-51.

Calleja J.A. and Gutiérrez F., (2011), Impact radiologique lié au transport par route de matières radioactives en Espagne, Radioprotection, 46, 331-343.

Chetty S., (1996), The case study method for research in small and medium-sized firms, International Small Business Journal, 15, 73-85.

Instituto Nacional de Estadística (2009). URL: http://www.ine.es/ (accessed: 01/11/10).

Law 31/95 on Prevention of Occupational Risks (1995), BOE N 269 of November $10^{\text {th }} 1995$.

Nuclear Safety Council and Health Institute Carlos III (2010), Epidemiological study: Possible radiological impacts of nuclear and radioactive installations and fuel cycle on human health.

http://www.csn.es/index.php?option=com content\&view=article\&id=14919 (accessed: 07/12/10)

Ortega X. and Jorba B., (1988), Ionizing Radiations, Ed. Universidad Politécnica de Cataluña.

Prosanz F.J., (2005), New developments for the assessment of embrittlement, Material Science and Engineering, 6, 191-196.

RD 1566 on safety counsellors for the transport of hazardous goods by road, rail or ship (1999), BOE $N^{\circ}$ 254 of October $20^{\text {th }} 1999$.

Recommendations of the 'International Commission on Radiological Protection', ICRP (1999), Publication 60, Pergamon Press, Oxford (1991). Spanish translation by the Spanish Society of Radiological Protection, Madrid (1995).

Spanish nuclear power plants (1995).

http://www.csn.es/index.php?option=com content\&view=article\&id=132\&ltemid=137\&lang=es

(accessed: 07/12/10)

Tanarro A., (1986), lonizing radiations: radioactive and X-ray facilities, Junta de Energía Nuclear.

Transport to the ATC (2006).

www.enresa.es/actividades y proyectos/raa/seguridad transporte raa (accessed: 05/03/10).

Tunaboylu K., Plaifair A. and Mariapillai N., (2001), Waste Transport and Public Safety, Technical Report PTR-01-03, Pangea Resources International, Baden, Switzerland.

U.S. DOE (2002), Final Environmental Impact Statement for a Geologic Repository for Disposal Spent Nuclear Fuel and High-Level Radioactive Wastes at Yucca Mountain, Nye County, Nevada, DOE/EIS-0250F, Washington, DC: Office of Civilian Radioactive Waste Management.

Yin, R. (1994), Case study research: Design and methods, Sage Publishing, Beverly Hills. 